\title{
PELATIHAN MODEL LITERASI INFORMASI TUJUH PILAR UNTUK MENINGKATKAN KEMAMPUAN MENGIDENTIFIKASI BERITA HOAX DEMI MENJAGA PERSATUAN DAN KESATUAN BANGSA KEPADA KELOMPOK PENGAJIAN IBU-IBU DI KELURAHAN PURBAYAN BAKI SUKOHARJO
}

\author{
Yudhistiro Pandu Widhoyoko, Arif Sutikno, Daryono \\ Program Studi Pendidikan Teknologi Informasi \\ Faklutas Keguruan dan IImu Pendidikan \\ Universitas Slamet Riyadi \\ yudhistirowidhoyoko@gmail.com
}

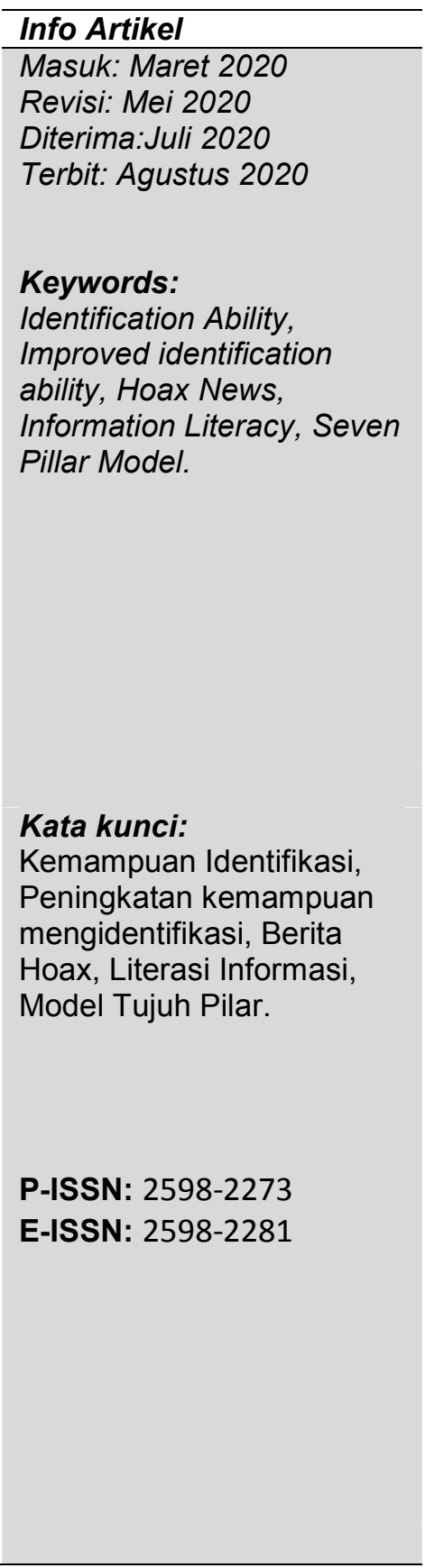

\begin{abstract}
The purpose of this training is to improve the ability to identify the truth of information using the Seven Pillar Information Literacy Model in order to become aware of how to know the correct source of information, be able to titrate information, be able to organize, apply, and communicate information to others in a way appropriate to the situation, and able compare and evaluate where the source of information obtained.

This research of society services was carried out in Purbayan, Baki, Sukoharjo in the Baitul Maqmur Study Group of PurbayanSukoharjo Prayer Groups of the Graha Kencana Public Corporation Study Group in Purbayan-Baki Sukoharjo. The method of implementing the service includes: (1) the method of approach that is carried out starting from the survey, licensing, and providing motivation for the women members of the study who will attend the training (2) the method of program implementation, including the preliminary stage, the socialization and audience stage, the implementation phase, and the final evaluation stage. The results were obtained that all participants in understanding how to distinguish false news and not using seven pillar literacy.
\end{abstract}

\begin{tabular}{l} 
Abstrak \\
\hline Tujuan dari pelatihan ini adalah untuk peningkatan kemampuan \\
mengidentifikasikan kebenaran suatu informasi menggunakan \\
Model Literasi Informasi Tujuh Pilar agar menjadi tahu cara \\
mengetahui sumber informasi yang benar, mampu meliterasi \\
informasi, mampu mengorganisir, menerapkan, dan \\
mengkomunikasikan informasi ke orang lain dengan cara sesuai \\
situasi, dan mampu membandingkan dan mengevaluasi dari \\
mana sumber informasi yang diperoleh. \\
Pengabdian ini dilaksanakan di Purbayan, Baki, Sukoharjo pada \\
Kelompok Pengajian Ibu-lbu Baitul Maqmur Purbayan-Baki \\
SukoharjoKelompok Pengajian Ibu-lbu Perum Graha Kencana \\
Purbayan-Baki Sukoharjo. Metode pelaksanaan pengabdian \\
meliputi: (1) metode pendekatan yang dilakukan mulai tahap \\
survei, perijinan, dan pemberian motivasi bagi ibu-ibu anggota \\
pengajian yang akan mengikuti pelatihan (2) metode pelaksanaan \\
program, meliputi tahap pendahuluan, tahap sosialisasi dan \\
audiensi, tahap pelaksanaan, serta tahap evaluasi akhir. \\
Diperoleh hasil bahwa seluruh peserta dalam memahami cara \\
membedakan berita bohong dan dan tidak menggunakan literasi \\
tujuh pillar.
\end{tabular}




\section{PENDAHULUAN}

Efek negative ini dikarenakan membludaknya informasi yang dapat dengan mudah diakses dari internet yang kemudian dibagikan secara massif dan serampangan oleh orang-orang yang bisa jadi, mereka ini tidak tahu kebenaran dari sebuah berita tersebut dapat menimbulkan permasalahan tersendiri bagi para pengguna media social tersebut. Masalahnya, tidak semua masyarakat Indonesia melek teknologi yang barangkali bisa secara mudah membedakan mana informasi yang benar dan mana yang salah. Kesulitan mengidentifikasi suatu informasi yang dibagikan memalui social media ini dapat membuat individu-individu dalam satu komunitas atau kelompok menjadi berjarak bahkan pecah jika perbedaanya terlalu tajam.

Adalah yang disebut dengan hoax, istilah yang diyakini ada sejak ratusan tahun yang lalu. Istilah ini muncul dari sebuah frasa pada sebuah mantra 'Hocus Pocus' yang mana, dahulu sering diucapkan para penyulap atau penyihir. Kabar bohong atau hoax, menurut Lynda Walsh, seorang associate Professor di University Nevada, Reno, dalam bukunya yang berjudul "Sins Against Science", adalah istilah dalam bahasa Inggris yang masuk sejak era industri, dan diperkirakan pertama kali muncul pada tahun 1808. Jauh sebelum itu, Alexander Boese, seorang Kurator, menulis dalam bukunya yang berjudul, "Museum of Hoaxes" menandai hoax pertama yang dipublikasikan adalah almanak atau penanggalan palsu yang dibuat oleh Isaac Bickerstaff alias Jonathan Swift pada 1709. Jadi, Hoax adalah pemberitaan palsu, bohong, dan bahkan fitnah yang dilakukan dengan sengaja untuk menipu atau mengakali pembaca agar supaya mempercayai sesuatu. Menurut fakta dan data dari Kementrian Komunikasi dan Informasi dikatakan bahwa ada sekitar hampir 800.000 situs di Indonesia yang terindikasi sebagai penyebar berita palsu atau yang sering disebut (HOAX).

Pertanyaanya adalah, bagaimana kita tahu bahwa suatu berita itu hoax atau bukan? Maka dari itu diperlukan sebuah kemampuan yang dapat menyaring informasi sesuai dengan kebutuhan. Mana informasi yang sekiranya dibutuhkan dan mana informasi yang tidak dibutuhkan. Hal in menjadi penting. Untuk dapat menjaga sebuah keutuhan kelompok-kelompok social yang berimbas pada persatuan dan kesatuan Bangsa dan Negara.

Maka kemudian, disinilah peran Literasi Informasi untuk menjawab kegagapan masyarakat atas keraguan sebuah informasi. Literasi Informasi adalah zaman dimana setiap pengguna informasi dituntut berpikir kritis atau "melek" akan informasi. Dengan pengertian bahwa semua pengguna informasi tanpa terkecuali haruslah memilah tiap informasi yang didapatkan, mengecek kebenaran akan informasi tersebut dan lebih jauh mengetahui alasan mengapa informasi tersebut dibuat dengan cara yang efektif dan efisien. (Trisiana, A. 2020); Wartoyo, Anita Trisiana. 2020);

Model yang digunakan dalam pelatihan Literasi Informasi adalah model Tujuh Pilar atau dalam istilah asli bahasa inggrisnya adalah Seven Pillars Model of 
Information Literacy. SCONUL (Standing Conference of National and University Libraries) di Inggris mengembangkan model konsdeptual yang disebut Seven Pillars of Information Literacy. Model Tujuh Pilar ini terdiri dari dua himpunan ketrampilan. Pertama adalah mengetahui bagaimana menentukan lokasi informasi serta mengaksesnya kemudian mengetahui bagaimana memahami serta menggunakan informasi.

Empat pilar pertama terdiri atas ketrampilan dasar yang disyaratkan untuk menentukan lokasi serta akses informasi yang terdiri dari, (1), Merekognisi kebutuhan informasi, mengetahui apa yang telah diketahui, mengetahui apa yang tidak diketahui dan mengidentifikasi kesenjangan antara yang diketahui dengan yang tidak diketahui. (2), Membedakan cara mengatasi kesenjangan, mengetahui sumber informasi mana yang paling besar peluangnya memuaskan kebutuhan. (3), Membangun strategi untuk menentukan lokasi informasi. (4), Menentukan lokasi dan akses informasi, mengetahui bagaimana mengakses sumbert informasi dan memeriksa alat untuk akses dan temu balik informasi. Sedangkan pilar ke lima sampai pilar ke tujuh merupakan ketrampilan tingkat lanjut yang diperlukan untuk memahami serta menggunakan informasi secara efektif.

Adapun ke tiga pilar tersebut ialah, (5) Membandingkan dan mengevaluasi, mengetahui bagaimana mengases relevansi dan kualitas informasi yang ditemukan. (6) Mengorganisasi, menerapkan dan mengkomunikasikan, mengetahui bagaimana merangkaikan informasi baru dengan informasi lama, mengambil tindakan atau membuat keputusan dan akhirnya bagaimana berbagi hasil temuan informasi tersebut dengan orang lain. (7) Sintesis dan menciptakan, mengetahui bagaimana mengasimilasikan informasi dari berbagai jenis sumber untuk keperluan menciptakan pengetahuan baru.

Ketrampilan dasar literasi informasi (pilar 1 sampai 4) merupakan dasar bagi semua isu dan topik, dapat diajarkan pada semua tingkat pendidikan. Ketrampilan tersebut juga diperkuat dan diperkaya melalui penggunaan berkala serta pembelajaran sepanjang hayat, umumnya melalui program dan sumber yang disediakan oleh perpustakaan. Untuk mencapai pilar 5 sampai 7, tantangan yang dihadapi lebih besar karena keanekaragaman orang.

Pengetahuan tentang kurangnya kemampuan literasi informasi itu secara spesifik didapatkan dari hasil wawancara dengan Kepala Kelompok Pengajian Ibuibu di Purbayan, Baki, Sukoharjo, didapatkan informasi bahwa dalam satu hari ada puluhan informasi melalui aplikasi WhatsApp dan Facebook dan juga lainnya yang mana sulit untuk dipilih dan dipilah mana yang perlu dan mana yang tidak. Bahkan beberapa informasi dapat menyulut perbedaan yang barangkali berujung pada perpecahan. Hal ini tentu saja meresahkan. Maka dari itu kelompok pengajian ibu-ibu ini akan mendapatkan pelatihan Literasi Informasi untuk dapat membedakan mana informasi yang diperlukan dan mana yang tidak diperlukan.

Berdasarkan analisis situasi yang telah dipaparkan, yang didapat dari hasil observasi dan wawancara, maka dapat diidentifikasi permasalahannay adalah 
kurang tahunya cara mengetahui sumber informasi yang benar, terlalu cepatnya membagikan atau meneruskan suatu informasi ke group atau orang lain. Kurangnya penguasaan Ibu-ibu kelompok pengajian meliterasi informasi, kurangnya kemampuan mengorganisir, menerapkan, dan mengkomunikasikan informasi ke orang lain dengan cara sesuai situasi, dan belum adanya kemampuan cara membandingkan dan mengevaluasi dari mana sumber informasi yang diperoleh.

Tujuan pelatihan peningkatan kemampuan mengidentifikasikan kebenaran suatu informasi menggunakan Model Literasi Informasi Tujuh Pilar kepada Kelompok Pengajian Ibu-lbu Baitul Maqmur Purbayan-Baki Sukoharjo dan Kelompok Pengajian Ibu-lbu Perum Graha Kencana Purbayan-Baki Sukoharjo agar supaya ibu-ibu kelompok pengajian Kelurahan Purbayan, Baki, Sukoharjo menjadi tahu cara mengetahui sumber informasi yang benar, mampu meliterasi informasi, mampu mengorganisir, menerapkan, dan mengkomunikasikan informasi ke orang lain dengan cara sesuai situasi, dan Mampu membandingkan dan mengevaluasi dari mana sumber informasi yang diperoleh.

\section{METODE PELAKSANAAN}

Transfer IPTEKS yang dilakukan Tim Pengabdian dilakukan pada tiap tahapan dengan menggunakan prinsip bahwa setiap inovasi yang diterima oleh mitra sebaiknya melalui proses mendengar, mengetahui, mencoba, mengevaluasi, menerima, meyakini, dan melaksanakan. Melalui proses-proses tersebut diharapkan inovasi dapat diadopsi secara berkesinambungan, serta target sasaran mempunyai kemampuan untuk mengembangkan inovasi yang telah disosialisasikan. Supaya setiap proses berlangsung dengan baik, maka penyampaian inovasi kepada mitra ditempuh melalui tahapan penjelasan, diskusi, praktek serta dilakukan tahapan pendampingan.

Metode yang dilakukan adalah sebagai berikut: pertama pendekatan secara partisipatif dan dialogis, yaitu dengan cara menghubungi kedua Ketua Kelompok Pengajian Kelurahan Purbayan terlebih dahulu. Setelah itu, Ibu-ibu kelompok pengajian tersebut dikumpulkan dan diajak bermusyawarah dengan tim pelaksana. Musyawarah disini yaitu tentang Program Pelatihan yang akan dilaksanakan serta kendala-kendala yang dimungkinkan timbul dalam pelaksanaan program ini, sehingga dalam musyawarah ini bisa mendapatkan solusi atas kendala tersebut. Setelah akan dilakukan pendampingan serta pelatihan kepada khalayak sasaran.

Metode pendekatan masalah dapat diuraikan pada Gambar 3 sebagai berikut. 


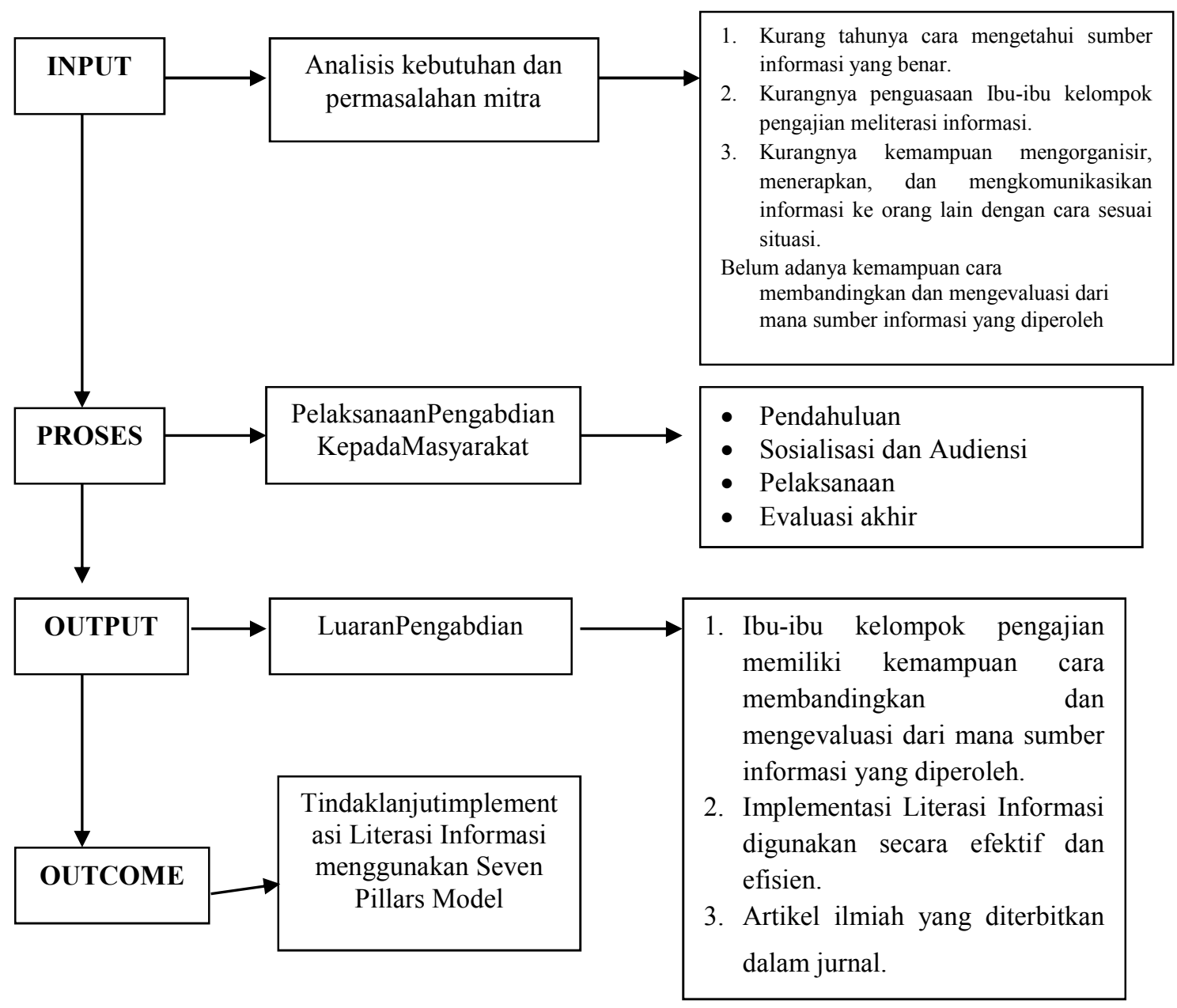

Gambar 4. Metode Pendekatan Masalah

\section{PEMBAHASAN}

Pengabdian kepada masyarakat ini dilaksanakan pada April 2019 yang dihadiri oleh seluruh peserta yaitu dari pegawai kelurahan Purbayan Kecamatan Baki Kabupaten Sukoharjo. Kegiatan ini berjalan dengan lancar dan seluruh peserta dengan antusias mengikuti kegiatan ini dari awal sampai akhir. Peserta mengikuti kegiatan pengabdian kepada Masyarakat ini dengan baik dan mereka berpartisipasi aktif selama kegiatan berlangsung.

Materi yang disampaikan pada kegiatan ini adalah tentang pelatihan mengidentifikasi kebenaran suatu informasi menggunakan model Literasi Informasi Tujuh Pilar. Pengabdian ini akan dilaksanakan di tempat mitra Kelompok Pengajian Ibu-lbu Baitul Maqmur Purbayan-Baki Sukoharjo dan Kelompok Pengajian Ibu-lbu Perum Graha Kencana Purbayan-Baki Sukoharjo. 
Penyampaian materi dalam kegiatan pengabdian kepada masyarakat ini disampaikan dengan metode ceramah, praktek, dan diskusi. Selama kegiatan berlangsung, semua peserta sangat antusias dengan cara berpartisipasi aktif. Setelah ceramah selesai, peserta mengajukan beberapa pertanyaan kaitannya dengan beberapa kendala komunikasi yang dihadapi ketika harus menyampaikan suatu informasi kepada masyarakat. Sebagian peserta menganggap bahwa penggunaan metode door to door dalam menyanpaikan undangan maupun informasi yang lain dianggap sudah kuno dan melelahkan.

Pada sesi diskusi, diketahui ternyata banyak peserta pengajian yang belum tahu bagaimana mengidentifikasi bahwa informasi itu dikategorikan benar dan valid atau tidak. Tentu saja selanjutnya mereka merasa semakin kesulitan untuk menakar dan mengukur seberapa hebatnyakah pengaruhnya jika beritaini tersebar. Karena, beberapa berita yang dikatergorikan hoax, mampu memecah belah bangsa dan Negara.
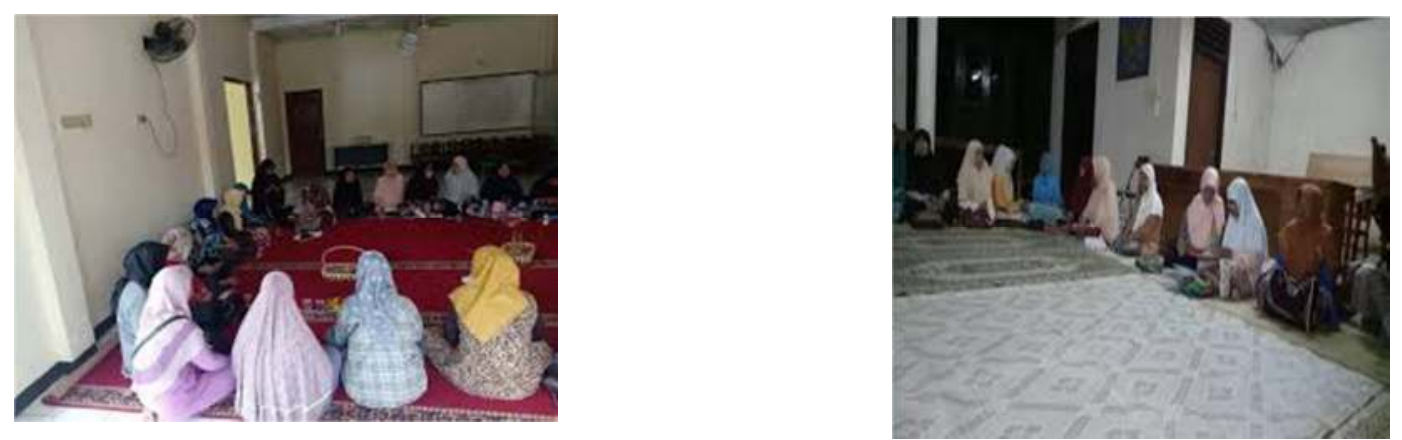

Gambar pelaksanaan peserta pelatihan.

\section{PENUTUP}

Pengabdian kepada masyarakat ini dilaksanakan pada April 2019 yang dihadiri oleh seluruh peserta yaitu dari Kelompok Pengajian Ibu-lbu Baitul Maqmur Purbayan-Baki Sukoharjo dan Kelompok Pengajian Ibu-lbu Perum Graha Kencana Purbayan-Baki Sukoharjo. Kegiatan ini berjalan dengan lancar dan seluruh peserta dengan antusias mengikuti kegiatan ini dari awal sampai akhir. Peserta mengikuti kegiatan pengabdian kepada Masyarakat ini dengan baik dan mereka berpartisipasi aktif selama kegiatan berlangsung.

Materi yang disampaikan pada kegiatan ini adalah tentang pelatihan mengidentifikasi kebenaran suatu informasi menggunakan model Literasi Informasi 
Tujuh Pilar. Pengabdian ini akan dilaksanakan di tempat mitra Kelompok Pengajian Ibu-lbu Baitul Maqmur Purbayan-Baki Sukoharjo dan Kelompok Pengajian Ibu-lbu Perum Graha Kencana Purbayan-Baki Sukoharjo.

Penyampaian materi dalam kegiatan pengabdian kepada masyarakat ini disampaikan dengan metode ceramah, praktek, dan diskusi. Selama kegiatan berlangsung, semua peserta sangat antusias dengan cara berpartisipasi aktif. Setelah ceramah selesai, peserta mengajukan beberapa pertanyaan kaitannya dengan beberapa kendala komunikasi yang dihadapi ketika harus menyampaikan suatu informasi kepada masyarakat. Sebagian peserta menganggap bahwa penggunaan metode door to door dalam menyanpaikan undangan maupun informasi yang lain dianggap sudah kuno dan melelahkan.

Pada sesi diskusi, diketahui ternyata banyak peserta pengajian yang belum tahu bagaimana mengidentifikasi bahwa informasi itu dikategorikan benar dan valid atau tidak. Tentu saja selanjutnya mereka merasa semakin kesulitan untuk menakar dan mengukur seberapa hebatnyakah pengaruhnya jika beritaini tersebar. Karena, beberapa berita yang dikatergorikan hoax, mampu memecah belah bangsa dan Negara.

\section{DAFTAR PUSTAKA}

Bawden, D. (2008). Origins and concepts of digital literacy. Dalam C. Lankshear\&M. Knobel (eds). Digital literacies : concepts, policies, and paradoxes. Pp:1532. New Yok: Peter Lang

Behrens, S. (1994). A conceptual analysis and historical review of information literacy. College and Research Libraries, 55,309-322.

Horton,Jr, Forest Woody.(2007). Understanding information literacy: a prime. Paris"UNESCO

Martin,A. (2008). Digital literacy and the"digital society:. Dalam C. Lanskhear \& M.Konel(eds). Digital literacies: concepts, policies, and paradoxes. New York:Peter Lang.

Sudarsono, Blasius et al. (2007; 2009), Literasi informasi (information literacy): pengantar untuk perpustakaan sekolah. Jakarta: Perpustakaan Nasional. 
Trisiana, A. 2020. Digital Literation Models For Character Education In Globalization Era : Digital Literation Models. Humanities \& Social Sciences Reviews, 8(1), 522-531. Https://Doi.Org/10.18510/Hssr.2020.8164

Trisiana, A. Sugiaryo, Rispantyo. 2019. Model Desain Pendidikan Kewarganegaraan di Era Digital sebagai Pendukung Sebagai Implementasi Pendidikan Karakter. Jurnal Civic Media Kajian Kewarganegaraan. Vol 16 (2). Pp 154-164

Wartoyo, Anita Trisiana. 2020. Project Citizen: Innovation And Challenges Of Education Learning Models To Improve Millenial Generation Characters. Journal of critical reviews (JCR) Volume: 7, Issue: 11: 750754. DOI: $10.31838 / j c r .07 .11 .134$ 